\title{
Editorial
}

\section{What's New in Acta Haematologica in 2018}

It is with great pleasure that I would like to update our readers on the last year's changes and achievements.

We welcome the new Editorial Board members and the new Associate Editor who joined us. All are leading figures in their field: Dr. Ulrike Nowak-Göttl, the new Associate Editor, Dr. Gautam Borthakur, Dr. Jan Burger, Dr. Nick Cross, Dr. Courtney Dinardo, Dr. Dan Douer, Dr. Morie Gertz, Dr. Elias Jabbour, Dr. Tapan Kadia, Dr. Hagop Kantarjian, Dr. Sam Schulman, Dr. John Seymour, Dr. Srdan Verstovsek, and Dr. Achy J. Yahalom.

This is also an opportunity to thank again Dr. Isaac Ben-Bassat, who served our journal as Editor-in-Chief for several decades and Dr. Campbell Tait for his service as Associate Editor. Dr. Ben-Bassat and Dr. Tait accepted my invitation to stay on board as members, and we are grateful to them for this.

We hope to continue and push our journal forward in view of its vision to publish clinical as well as innovative translational research, to apply high standards of clinical and scientific reporting, to shorten the time from submission of papers to the final decision, to raise the impact factor of the journal, and finally to increase the number of readers and submissions.

In line with our policy of keeping the high standards of our journal, the journal's rejection rate is between 70 $75 \%$.

I am happy to say that the impact factor has been rising with a current impact factor of 1,307.
In addition to the standard article types, we have recently launched several new sections: "Solving Clinical Problems in Hematology" - exceptional clinical observations made on 1 or a small number of patients with unique, generalizable insights; "Images in Clinical Hematology" - visual descriptions of a defined hematological condition; "Meet the Expert" - short review articles describing the personal viewpoint of a key opinion leader; "Patient Reported Outcomes" - in line with the fact that patient-centered medicine is becoming important; and "Interdisciplinary Perspectives in Hematology" - while hematooncology is becoming very sophisticated in certain areas, it is also growing into being more interactive with other disciplines in medicine. We are happy to launch this new section in the present issue of Acta Haematolgica with the contribution of Dr. Nili SchamrothPravda and Dr. Ran Kornowski on the topic of "Unmet Needs and Therapeutic Strategies in Cardio-HematoOncology". We hope that others will follow in the near future.

On behalf of the Editorial Board, I would like to thank our contributors for their efforts and encourage our readers to continue to find useful and interesting information in our journal as well as consider submitting their work to Acta Haematologica.

Pia Raanani, Editor-in-Chief

\section{KARGER}

E-Mail karger@karger.com

www.karger.com/aha
(C) 2018 S. Karger AG, Basel
Prof. Pia Raanani

Institute of Hematology, Davidoff Cancer Center, Rabin Medical Center Beilinson Campus, 39 Jabotinski Street

Petah Tiqwa 49100 (Israel)

E-Mail praanani@012.net.il 